\title{
Correction to: Brief Report: Use of the Infant-Toddler Checklist in Infant Siblings of Children with Autism Spectrum Disorder
}

\author{
Chandni Parikh ${ }^{1} \cdot$ Ana-Maria losif $^{2} \cdot$ Sally Ozonoff ${ }^{1}$
}

Published online: 20 April 2020

(c) Springer Science+Business Media, LLC, part of Springer Nature 2020

\section{Correction to: Journal of Autism and Developmental Disorders https://doi.org/10.1007/s10803-020-04468-6}

The original version of the article unfortunately contained a mistake in the Results and Discussion section.

The corrected sentences are given below:

1. In the Results section (paragraph 2): "The psychometric values were moderate, with strongest indices at 24 months: $\mathrm{SE}=78 \%$ (95\% CI 64-91\%), $\mathrm{SP}=83 \%$ (95\% CI $78-89 \%), \mathrm{PPV}=52 \%$ (95\% CI 40-65\%), and NPV $=94 \%$ (95\% CI 90-98\%)."

Instead should say, "SE $=77 \%$ (95\% CI 64-90\%), SP = $85 \%$ (95\% CI 80-91\%), PPV $=55 \%$ (95\% CI 42-68\%), and $\mathrm{NPV}=94 \%$ (95\% CI 90-98\%)".
2. In the Discussion section (paragraph 2), "Longitudinally, SE ranged from 52 to $63 \%$ and SP from 42 to $83 \%$ in our study."

Instead should say, "Longitudinally, SE ranged from 51 to $62 \%$ and SP from 42 to $85 \%$ in our study".

Publisher's Note Springer Nature remains neutral with regard to jurisdictional claims in published maps and institutional affiliations.

The original article can be found online at https://doi.org/10.1007/ s10803-020-04468-6.

Chandni Parikh

cparikh@ucdavis.edu

1 Department of Psychiatry \& Behavioral Sciences, MIND Institute, University of California-Davis Health, 2825 50th Street, Sacramento, CA 95817, USA

2 Department of Public Health Sciences, University of California-Davis, Davis, CA, USA 